\section{Familial Creutzfeldt-Jakob Disease without Periodic EEG Activity}

\author{
Gretchen E. Tietjen, MD, and Ivo Drury, MB BCh
}

Four members of a kindred with Creutzfeldt-Jakob disease are reported, in whom myoclonus did not develop and in whom serial electroencephalograms performed late in their illness failed to show periodic sharp wave complexes. Otherwise, the patients' disease duration, clinical features, and neuropathological findings were similar to those described in sporadic cases of Creutzfeldt-Jakob disease. Our findings and those reported by others suggest that periodic electroencephalographic activity may be rare in familial forms of Creutzfeldt-Jakob disease, as it is in other slow transmissible encephalopathies.

Tietjen GE, Drury I. Familial Creutzfeldt-Jakob disease without periodic EEG activity.

Ann Neurol 1990;28:585-588

Although most cases of Creutzfeldt-Jakob disease (CJD) are sporadic, 5 to $15 \%$ are clustered in families $[1,2]$. Clinically, CJD is characterized by rapidly progressive dementia, myoclonus, and cerebellar and visual dysfunction [3]. There are no confirmatory serological or radiographic tests. Electroencephalograms (EEGs), however, may be useful in establishing a diagnosis in those suspected of having the illness. Typical features are 1 to $2 \mathrm{~Hz}$ periodic sharp wave complexes (PSWCs), which may be present as early as 3 weeks after onset and are seen in $88 \%$ of EEGs after the 12 th week of illness [4].

We report, from a kindred of more than 250 members, 4 persons with pathologically verified CJD who showed no myoclonus and no PSWCs in serial EEGs late in the course of illness.

\section{Material and Methods}

Identifying data and clinical features of the 4 patients are summarized in the Table. The case reports for Patients 3 and 4 follow. Patients 1 and 2 were Patients III- 1 and III-2 in the report of Bertoni and colleagues [5]. Our four proven cases

From the Department of Neurology, University of Michigan, Ann Arbor, MI.

Presented in part at the 114th Annual Meeting of the American Neurological Association, New Orleans, L.A, Sept 25, 1989.

Received Nov 30, 1989, and in revised form Mar 23 and May 8, 1990. Accepted for publication May 8, 1990.

Address correspondence to Dr Drury, Department of Neurology, University of Michigan, 1500 East Medical Center Drive, Ann Arbor, MI 48109 . derive from generation III of a large family, with three probable cases in generation II, another case in generation I, and a possible case in generation III (Fig 1). Individuals in generations IV, V, and beyond have not yet reached the age at which the disease is expected to manifest.

\section{Patient 3}

A 64-year-old woman with diabetes developed generalized malaise in July 1985. Over the next 3 months, she became demented and increasingly ataxic, and within 6 months was incontinent, confined to bed, and unable to recognize family and friends. The patient's family history was notable for rapidly progressive dementia in her paternal grandfather, father, two paternal uncles, and three cousins. All were farmers and ate a homemade sausage containing hog brain.

Neurological examination after 25 weeks showed lethargy and severe dysarthria. Single-step commands were followed inconsistently. The patient stood on a broad base with assistance but could not walk. Upward gaze was restricted. Spontaneous movements were markedly diminished. There was cogwheel rigidity and dysmetria, but no myoclonic jerks. Muscle stretch reflexes were symmetric but absent at the ankles. Both plantar responses were flexor. Pinprick elicited a purposeful withdrawal.

The patient died of pneumonia 41 weeks after the initial presentation.

\section{Patient 4}

The 59-year-old sister of Patient 3, who was also diabetic, was well until August 1988. She complained of blurred vision and became forgetful. Within 2 weeks she was ataxic and dysarthric; by 6 weeks she was confined to bed, incontinent, and unable to feed herself.

Neurological examination after 9 weeks showed somnolence and ataxic dysarthria. The patient recognized her husband and some simple objects. She was unable to stand. She pursued objects in a horizontal direction only. Vertical range was full with oculocephalic maneuvers. Her limbs were rigid, and spontaneous movements were diminished and dysmetric. There were no myoclonic jerks, even when she was startled. Muscle stretch reflexes were normal in the arms, but absent in the legs. The right plantar response was extensor. The patient withdrew purposefully to painful stimuli. She died of pneumonia 12 weeks after the initial presentation.

\section{EEG Methodology}

Nine EEGs were performed on the 4 patients. Recordings included bipolar and referential montages with electrodes applied according to the international 10-20 system. Although the records were obtained at different stages of the illness, at least one EEG was performed later than 12 weeks after onset in 3 patients (Patients 1,2,3), and 2 patients (Patients 1,4 ) had studies within 2 weeks of death. Recordings included wakefulness in all cases, as well as sleep in Patient 3. Hyperventilation, photic stimulation, and attempts at arousal (including sudden loud auditory stimuli) were performed during each study. Mild background slowing consisted of predominant alpha activity posteriorly with excessive intermixed theta activity. Moderate slowing consisted of a background in the theta range with intermixed delta activity. 


\begin{tabular}{|c|c|c|c|c|c|c|c|c|c|c|c|c|}
\hline \multirow[b]{3}{*}{$\begin{array}{l}\text { Patient } \\
\text { No. }\end{array}$} & \multicolumn{3}{|c|}{ Identifying Data } & \multirow{2}{*}{\multicolumn{6}{|c|}{ Clinical Features }} & \multicolumn{3}{|c|}{ EEG leatures } \\
\hline & \multirow{2}{*}{$\begin{array}{l}\text { Age of } \\
\text { Onset } \\
\text { (yr) }\end{array}$} & \multirow[b]{2}{*}{$\begin{array}{l}\text { Year of } \\
\text { Onset }\end{array}$} & \multirow{2}{*}{$\begin{array}{l}\text { Length of } \\
\text { Tllness } \\
\text { (wk) }\end{array}$} & & & & & & & \multirow{2}{*}{$\begin{array}{l}\text { Week } \\
\text { of } \\
\text { Illncss }\end{array}$} & \multirow{2}{*}{$\begin{array}{l}\text { Degree of } \\
\text { Background } \\
\text { Slowing }\end{array}$} & \multirow[b]{2}{*}{ PSWCs } \\
\hline & & & & Dementia & Ataxia & Myoclonus & $\begin{array}{l}\text { Supranuclear } \\
\text { Gaze Palsy }\end{array}$ & Extrapyramidal & Pyramidal & & & \\
\hline \multirow[t]{2}{*}{1} & \multirow[t]{2}{*}{44} & \multirow[t]{2}{*}{1972} & \multirow[t]{2}{*}{19} & \multirow[t]{2}{*}{+} & \multirow[t]{2}{*}{+} & \multirow[t]{2}{*}{-} & \multirow[t]{2}{*}{+} & \multirow[t]{2}{*}{-} & \multirow[t]{2}{*}{ - } & 6 & Mild & - \\
\hline & & & & & & & & & & 17 & Moderate & - \\
\hline \multirow[t]{2}{*}{2} & \multirow[t]{2}{*}{48} & \multirow[t]{2}{*}{1981} & \multirow[t]{2}{*}{22} & \multirow[t]{2}{*}{+} & \multirow[t]{2}{*}{+} & \multirow[t]{2}{*}{$?$} & \multirow[t]{2}{*}{+} & \multirow[t]{2}{*}{-} & \multirow[t]{2}{*}{+} & 5 & Mild & - \\
\hline & & & & & & & & & & 17 & Moderate & - \\
\hline \multirow[t]{3}{*}{3} & \multirow[t]{3}{*}{64} & \multirow[t]{3}{*}{1985} & \multirow[t]{3}{*}{41} & \multirow[t]{3}{*}{+} & \multirow[t]{3}{*}{+} & \multirow[t]{3}{*}{--} & + & + & - & 22 & Mild & - \\
\hline & & & & & & & & & & 25 & Moderate & - \\
\hline & & & & & & & & & & $3 \mathrm{I}$ & Moderate & - \\
\hline 4 & 59 & 1988 & 12 & + & + & - & + & + & + & 6 & Mild & - \\
\hline & & & & & & & & & & 10 & Moderate & - \\
\hline
\end{tabular}

PSWCs = periodic shorr wave complexes.

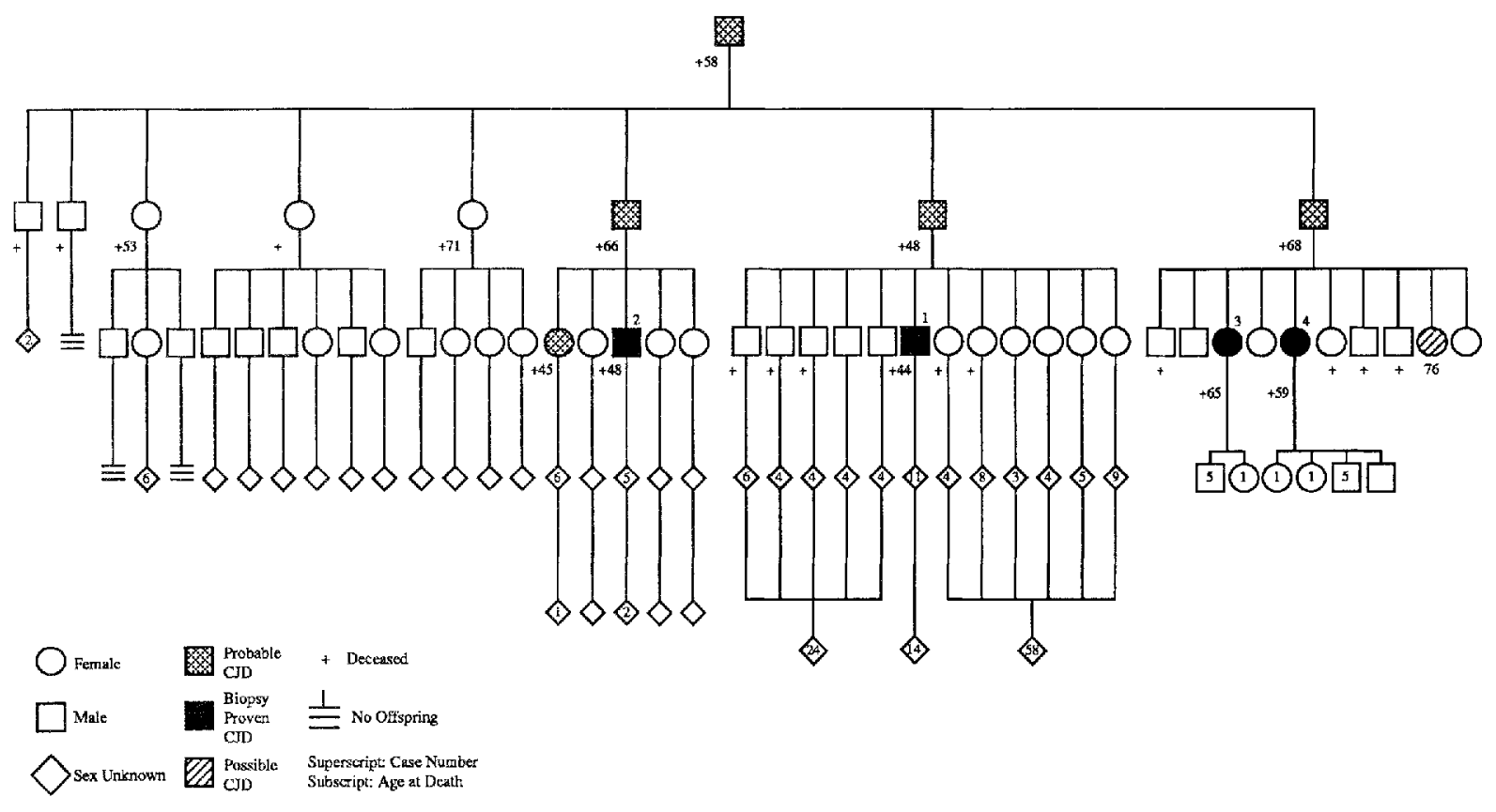

Fig 1. Pedigree of family. (CJD $=$ Creutzfeldt-Jakob disease.)

\section{Results}

\section{EEG and Clinical Correlations}

Each patient was initially seen with similar clinical features-rapidly progressive dementia, cerebellar ataxia, and vertical supranuclear gaze palsy. With the possible exception of Patient 2 (indicated by a question mark in the Table), who was noted by a nonmedical observer to have jerked in his sleep during the last stage of his illness, myoclonus was absent. As illustrated in the Table, EEGs recorded during the course of illness showed progressive background slowing but no PSWCs, even in recordings after the 12 th week of illness or shortly before death. Figure 2 is a sample of EEG activity from Patient 3 during week 31 of her illness. The record shows moderate background slowing without PSWCs. Figure 3 is a sample of EEG activ- ity from Patient 4 during week 10, 2 weeks before her death. Again, there is a moderately severe background disturbance but no PSWCs.

\section{Patbological Findings}

Pathological observations confirmed the diagnosis of CJD in each patient. In Patients 1 and 4, vacuolization of the gray matter neuropil was more prominent in the cerebellar than in the cerebral cortex. In Patient 1, the vacuolization was most evident in the cerebellum, hippocampal formation, thalamus, and pons, and least evident in the cerebral cortex. Moderate spongiform changes were seen in the basal ganglia and other parts of the brainstem. An uncommon distribution of neuropil vacuolization was seen in Patient 4 as well. Round vacuoles, 5 to $10 \mu \mathrm{m}$ in diameter, were most 


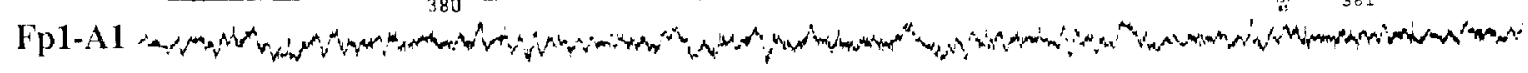

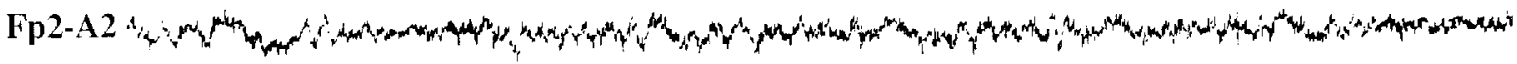

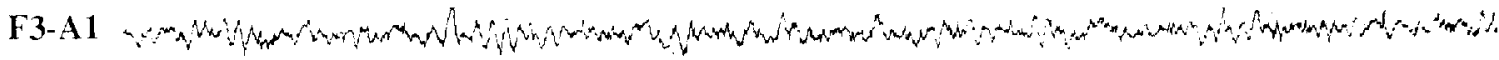

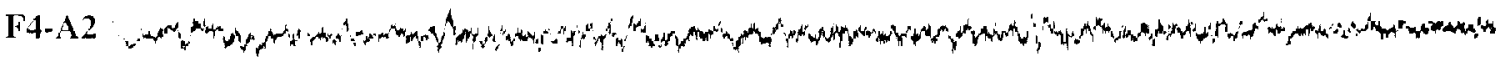

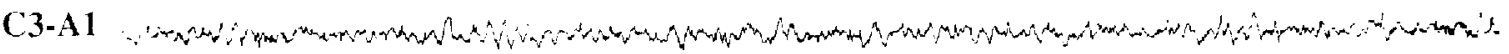

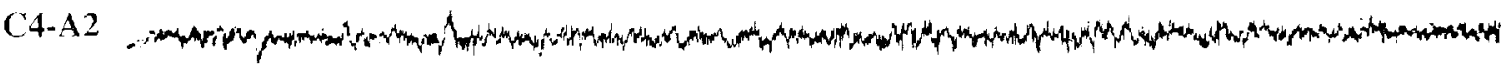

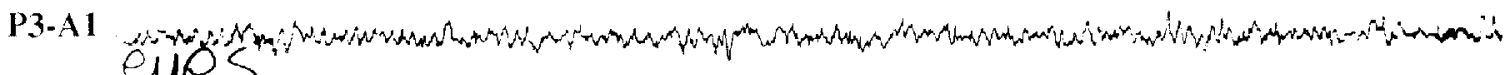

P4-A2 mente,

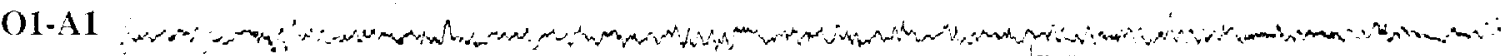

O2-A2 : 2 :

Fig 2. EEG from Patient 3 in week 31 of illness. Maderate background slowing is present without periodic sharp wave complexes.

abundant in the cerebellar and parahippocampal cortex. These vacuoles even extended through the subiculum into the hippocampus, where they were present in almost all of the neuropil as well as between the nerve cell bodies in the pyramidal cell layer. Basal ganglia, inferior colliculi, and parts of the temporal cortex and substantia nigra were also involved.

In the other 2 patients, the spongiform changes were greatest in the cerebral cortex. The principal findings in Patient 2 were fine vacuoles 5 to $15 \mu \mathrm{m}$ in diameter in the neocortex. There was no obvious

Fig 3. EEG from Patient 4 in week 10 of illness and within 2 weeks of death. Moderate background slowing without periodic sharp wave complexes is notable. neuronal loss in these areas. There was proliferation of hypertrophied fibrillary astrocytes throughout the cortex. Vacuolization was slight or absent in other gray matter structures. In Patient 3, vacuoles 3 to $5 \mu \mathrm{m}$ in diameter were most prominent in the neocortex and basal ganglia. Hypertrophied astrocytes were also seen. The cerebellar cortex showed parenchymal atrophy and astrocyte hypertrophy, but vacuolization was scant. Plaques were absent in each instance.

\section{Discussion}

Based on the largest series of patients with neuropathologically verified CJD, it has been suggested that the absence of both PSWCs and involuntary movements virtually excludes the diagnosis from consideration [3]. Cerebellar dysfunction, supranuclear gaze palsy, and dementia were prominent early fearures in each of the

Fp1-A1 "W

Fp2-A2 2 are

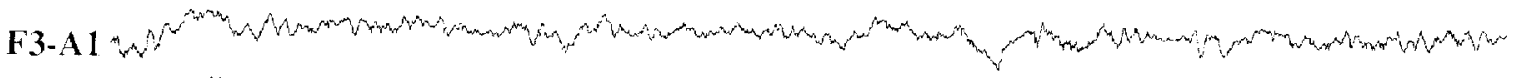

F4-A2 a

C3-A1 1 mith

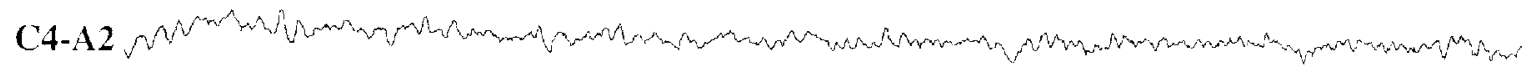

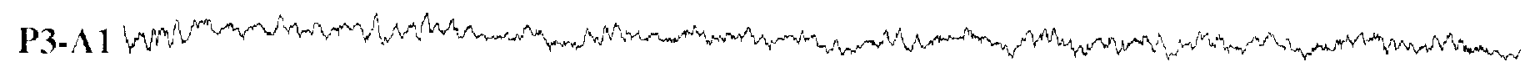

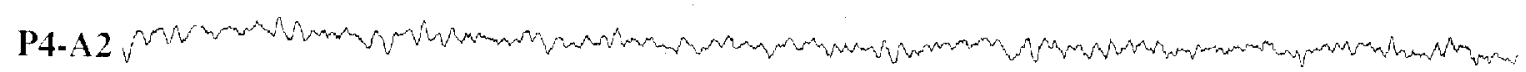

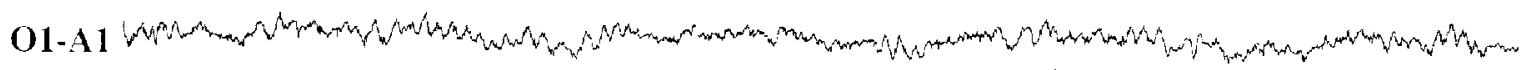

$\mathrm{O} 2-\mathrm{A} 2$

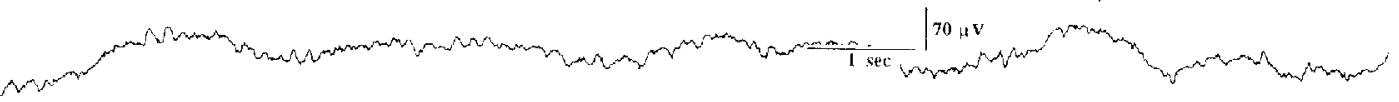


4 members of our kindred with histologically proven disease, whereas myoclonus and PSWCs were absent.

Eighty-eight percent of patients with CJD exhibit PSWCs within 12 weeks of onset of clinical symptoms [4]. PSWCs may abate late in the clinical course. The timing and frequency of recordings thus become important when discussing the absence of characteristic activity. Three of our patients had a total of 5 recordings at greater than 12 weeks into the illness, and 2 patients, including 1 with a total clinical course of 12 weeks, had EEGs performed within 2 weeks of death. PSWCs have been noted to occur less frequently $(55 \%)$ in patients with disease of greater than 24 months' duration [6]. All the affected members of our kindred had the short course typical of CJD.

The familial form of $\mathrm{CJD}$ composes 5 to $15 \%$ of all reported cases $[1,2]$. To our knowledge, no comprehensive evaluation of EEG characteristics in familial cases exists. It appears, however, that PSWCs are less common in familial than in sporadic CJD, although the clinical characteristics are not dramatically different [7-9]. Furthermore, in 4 familial cases of long-duration experimentally transmissible CJD, there were no PSWCs in 2 patients. The areas of gray matter involvement were not specified in this report [6].

The absence of PSWCs may be due to disease topography. Although the underlying mechanism of PSWCs is unknown, careful EEG and neuropathological correlation suggest that they occur consistently only with diffuse cortical and subcortical gray matter involvement [10]. The pathological findings in our kindred were notable for the relative sparing of cerebral cortex in Patients 1 and 4, and the absence of thalamic involvement in Patients 2 and 3, although other deep gray structures (basal ganglia) were affected. The observation that patients with CJD and prominent cerebellar symptoms are less likely to exhibit PSWCs may be secondary to reduced cerebral cortical involvement [9]. It must be noted, however, that of the 7 patients with CJD reported by Zochodne and co-workers [11], 2 had extensive involvement of superficial and deep gray matter structures and the typical disease duration, but no PSWCs on serial EEGs.

Clinical and experimental knowledge of other slow, transmissible encephalopathies provides additional evidence for genetic influence on the EEG pattern. Kuru, a spongiform encephalopathy with marked cerebellar signs, no myoclonus, and a late dementia, is not associated with PSWCs even in recordings just before death [12]. That Kuru-infected brains, when inoculated into rhesus monkeys, produced myoclonus and generalized spike-wave complexes in recordings from dural electrodes suggests that the EEG pattern is host dependent [13]. In Gerstmann-Straussler-Scheinker disease (GSSD), characterized by familial ataxia and dementia of long duration, myoclonus seldom occurs and EEGs are normal or mildly abnormal without PSWCs. Patho- logical features in GSSD are quite distinct from those of CJD; however, even in a GSSD kindred with predominant involvement of telencephalic and diencephalic structures and sparing of the cerebellum, PSWCs were not seen $[14,15]$. The absence of PSWCs in familial CJD suggests a genetic influence on the expression of the EEG pattern that may not be explained by disease topography alone.

We thank Constance D'Amato and Dr Sam Hicks for assistance with the neuropathological material and Suzanne French-Willis for manuscript preparation. Dr Glen Ackerman provided two EEGs from Patient 3. Dr Jeffrey Shepard provided an EEG performed on Patient 4 .

\section{References}

1. Brown P, Cathala F, Raubertas RF, et al. The epidemiology of Creutzfeldt-Jakob disease: conclusion of a 15-year investigation in France and review of the world literature. Neurology 1987; 37:895-904

2. Masters CI, Harris JO, Gajdusek DC, et al. Creutzfeldt-Jakob disease: patterns of worldwide sccurrence and the significance of familial and sporadic clustering. Ann Neurol 1979;5:177188

3. Brown P, Cathala F, Castaigne P, Gajdusek DC. CreutzfeldtJakob disease: clinical analysis of a consecutive series of 230 neuropathologically verified cases. Ann Neurol 1986;20:597602

4. Levy SR, Chiappa KH, Burke CJ, Young RR. Early evolution and incidence of electroencephalographic abnormalities in Creutzfeldt-Jakob disease. J Clin Neurophysiol 1986;3:1-21

5. Bertoni JM, Label LS, Sackellares JC, Hicks SP. Supranuclear gaze palsy in familial Creutzfeldr-Jakob disease. Arch Neurol 1983;40:618-622

6. Brown P, Rodgers-Johnson P, Cathala F, et al. CreutzfeldtJakob disease of long duration: clinicopathological characteristics, transmissibility and differential diagnosis. Ann Neurol 1984;16:295-304

7. Haltia M, Kovanen J, Van Crevel H, et al. Familial CreutzfeldtJakob disease. J Neurol Sci 1979;42:381-389

8. Kuritzky A, Davidovitch S, Sandbank U, Bechar M. Normal EEG in Creutzfeldt-Jakob disease. Neurology 1980;30:11341135

9. Cartier L, Galvez S, Gajdusck DC. Familial clustering of the ataxic form of Creutzfeldt-Jakob disease with Hirano bodies. J Neurol Neurosurg Psychiatry 1985; 48:234-238

10. Gloor P, Kalabay O, Giard N. The electroencephalogram in diffuse encephalopathies: electroencephalographic correlates of grey and white matter lesions. Brain 1968;91:779-802

11. Zochodne DW, Young GB, McLachlan RS, et al. CreutzfeldtJakob disease without periodic sharp wave complexes: a clinical, electroencephalographic and pathologic study. Neurology 1988;38:1056-1060

12. Cobb WA, Hornabrook RW, Sanders S. The EEG of kuru. Electroencephalogr Clin Neurophysiol 1973;34:419-427

13. Bert J, Vuillon-Cacciuttolo G, Balzamo E, et al. Experimental kuru in the rhesus monkey: a study of EEG modifications in the waking state and during sleep. Electroencephalogr Clin Neurophysiol 1978;45:611-620

14. Heston LI, Lowther DL, Leventhal CM. Alzheimer's disease: a family study. Arch Neurol 1966;15:225-233

15. Nochlin D, Sumi SM, Bird TD, et al. Familial dementia with PrP-positive amyloid plaques: a variant of Gerstmann-Strassler syndrome. Neurology 1989;39:910-918 